\title{
Prospective evaluation of microscopic extension using whole-mount preparation in patients with hepatocellular carcinoma: Definition of clinical target volume for radiotherapy
}

Weihu Wang ${ }^{1}$, Xiaoli Feng ${ }^{2}$, Tao Zhang ${ }^{1}$, Jing Jin' ${ }^{1}$ Shulian Wang ${ }^{1}$, Yueping Liu', Yongwen Song ${ }^{1}$, Xinfan Liu', Zihao $\mathrm{Yu}^{1}$, Yexiong $\mathrm{Li}^{1 *}$

\begin{abstract}
Background: To define the clinical target volume (CTV) for radiotherapy in patients with hepatocellular carcinoma (HCC).

Methods: A prospective study was conducted to histologically evaluate the presence and the distance of microscopic extension (ME) for resected HCC on the basis of examination of whole-mount preparations of carcinoma tissue sections.
\end{abstract}

Results: A total of 380 whole-mount slides prepared from tumor samples of 76 patients with HCC were examined. Patients with elevated pretreatment AFP levels exhibited higher risk of ME as compared to those with normal pretreatment AFP levels (93.9\% vs. $69.8 \%, P<0.01$ ). ME positivity was $16.7 \%$ for Grade 1, $79.1 \%$ for Grade 2 , and 96.3\% for Grade 3 tumors $(P<0.01$ ). The mean distance of ME was $0.0 \pm 0.1 \mathrm{~mm}$ (range $0-0.2 \mathrm{~mm}$ ) for Grade 1, $0.9 \pm 0.9 \mathrm{~mm}$ (range 0-4.5 mm) for Grade 2, and $1.9 \pm 1.9 \mathrm{~mm}$ (range 0-8.0 mm) for Grade 3 tumors $(P<0.01$ ).

Conclusions: The CTV margins for tumor Grades 1, 2, and 3 HCC, are recommended to be $0.2 \mathrm{~mm}, 4.5 \mathrm{~mm}$, and $8.0 \mathrm{~mm}$ beyond the gross tumor margin, respectively, to account for possible ME of the tumors in all patients.

\section{Background}

Hepatocellular carcinoma (HCC) is the fifth most common malignancy and the third leading cause of cancer mortality worldwide [1]. It is estimated that in 2009, there will be 22,620 new cases of liver cancer and 18,160 related deaths in America [2]. It is the third most common cancer and the second leading cause of cancer-related death in China [3,4]. The mainstay of therapy is surgical resection with a 5 -year survival rate ranging from 30 to $70 \%[5,6]$. Unfortunately, less than $20 \%$ of HCC patients are eligible for surgery; surgery is ruled out in many patients because of inadequate liver function reserve, the multifocal nature of the disease, and the proximity to and/or involvement of vascular or

\footnotetext{
* Correspondence: yexiong@yahoo.com

'Department of Radiation Oncology, Cancer Hospital, Chinese Academy of Medical Sciences (CAMS) and Peking Union Medical College (PUMC), Beijing 100021, P.R. China

Full list of author information is available at the end of the article
}

biliary structures $[7,8]$. Traditionally, the role of radiotherapy in the management of $\mathrm{HCC}$ has been limited by the low tolerance of the liver to radiation. However, recent advances in radiation techniques, such as threedimensional conformal radiation therapy (3D-CRT), intensity-modulated radiation therapy (IMRT), imageguided radiation therapy (IGRT), proton therapy, tumor-tracking, and respiratory gating techniques, have allowed the administration of high radiation doses to the primary tumor with sparing of the normal liver tissue $[9,10]$. Thus, the use of radical radiotherapy for unresectable HCC has increased dramatically in recent years, and promising results have been achieved [11-13]. In a radiotherapy setting, a tissue volume inclusive of the subclinical lesions in addition to the gross tumor is defined as clinical target volume (CTV). Modern imaging techniques enable precise delineation of gross tumor volume (GTV); however, none of the available 
imaging techniques enable the detection of the actual distance of the microscopic extension (ME) of HCC. It has not been possible to clearly define the CTV of HCC. Taking ME into account, a margin of 1.0 to $1.5 \mathrm{~cm}$ is arbitrarily added to the GTV to obtain the CTV [11-13]. It remains to be ascertained whether this margin is adequate to cover ME in patients with HCC. A narrow margin is associated with the increased risk of local failure, while a generous margin results in increased radiation damage to normal tissues. Therefore, guidelines for the extent of ME to be included within the radiation volume would be very useful in clinical practice. In this prospective study, we histologically evaluated the ME of HCC using whole-mount slides that should allow for a more representative assessment of the ME by increasing the amount of tissue examined compared to routine small histopathologic slides and defined the CTV as precisely as possible.

\section{Materials}

\section{Case selection}

Between June, 2007, and March, 2009, we prospectively enrolled 76 patients with pathologically diagnosed HCC who underwent tumor resection at the Cancer Institute and Hospital, Peking Union Medical College and Chinese Academy of Medical Sciences (Beijing, China). The pretreatment evaluation for all patients consisted of a complete history taking, physical examination, serological tests to screen for hepatitis B virus (HBV) and hepatitis $\mathrm{C}$ virus (HCV), $\alpha$-fetoprotein (AFP) assay, prothrombin time test (PT), complete blood counts, serum biochemical tests, abdominal computed tomography $(\mathrm{CT})$ with arterial- and portal-venous-phase imaging or MRI, and chest radiography. The time scale from imaging studies and laboratory tests to surgery was within 3 weeks before surgery. The criteria for inclusion in this study were as follows: (1) resectable hepatic lesion with clinical stage I and II disease determined according to the American Joint Committee on Cancer (AJCC 2002); (2) radical resection with a margin $\geq 1 \mathrm{~cm}$ around the gross tumor; (3) detection of a single lesion without satellite nodules in the pretreatment CT or during the operation; (4) no history of previous treatment. The protocol was approved by the institutional review boards, and written informed consent was obtained from all the patients.

\section{ME measurement}

After fixation of the resected specimen in 13\% neutral buffered formalin for $\geq 12 \mathrm{~h}$, transverse sections were obtained with an average thickness of $10 \mathrm{~mm}$, which were completely embedded in paraffin blocks. The paraffin blocks were cut into $4-\mu \mathrm{m}$-thick sections, and whole mount slides of these tissues were stained with hematoxylin and eosin (HE) and evaluated using a light microscope (Olympus BX40; Olympus, Tokyo, Japan). To avoid interobserver variations, the same pathologist (Xiaoli Feng) who particularly experienced in the assessment of hepatic lesions assessed all the slides and identified evidence of ME. ME was considered as positive if extension was detected microscopically, even if it was absent on imaging studies. If a tumor had multiple MEs, the longest distance between the tumor margin of the ME was recorded. ME was determined by light microscopy at a magnification of $\times 40$ and was confirmed, if required, by examination at $\times 100$ magnification.

The following features were recorded for each case: (1) ME status (positive versus negative), defined as positive if ME was identified; (2) ME distance, defined as the maximum linear distance from the capsular margin of the primary gross tumor to the farthest extent of the ME. We did not account for tissue shrinkage in this study because of the fixation of the tumor sections.

\section{Statistical analysis}

Statistical analysis was performed using SPSS version 11.0 statistical package (SPSS Inc., Chicago, IL). The clinical characteristics were analyzed using a chi-square test or Fisher's exact test (two-tailed) for categorical variables and logistic regression analysis for continuous variables. The Student's unpaired $t$ test was used to determine the significance of the difference between the 2 sample means. The association of these characteristics with ME distance was analyzed using logistic or linear regression models. Multivariate analyses were performed using a multiple logistic regression model. A $P$ value less than or equal to 0.05 was considered statistically significant.

\section{Results}

\section{Patient characteristics}

Patient characteristics and ME status are summarized in Table 1. The median age at the time of operation was 53 years (range, $25-78$ years). The median pretreatment AFP level was $13.1 \mathrm{ng} / \mathrm{ml}$ (mean, $1776.9 \mathrm{ng} / \mathrm{ml}$; range, $1 \sim 50781 \mathrm{ng} / \mathrm{ml}$ ). The median tumor size measured on enhanced CT was $5.0 \mathrm{~cm}$ (mean, $5.1 \mathrm{~cm}$; range $1.6-10.2 \mathrm{~cm}$ ) in the greatest dimension. Only 1 of the patients had Child-Pugh Class B cirrhosis, while the others had Child-Pugh Class A cirrhosis.

\section{Factors associated with the presence of ME}

In this study, the average number of slides for each patient investigated histologically was 5 (range 211 slides), and 380 slides of these tumor specimens were reviewed. Of the 76 patients with HCC, 61 (80.3\%) patients had ME, and 15 (19.7\%) patients did not have ME. As shown in Table 1, factors associated with the 
Table 1 Patient characteristics and ME status

\begin{tabular}{|c|c|c|c|}
\hline & Patients & ME positive & \\
\hline Characteristic & No (\%) & $\%$ & $P$ value \\
\hline Age (y) & & & NS \\
\hline$\leq 60$ & $39(51.3)$ & 87.2 & \\
\hline$>60$ & $37(48.7)$ & 73.0 & \\
\hline Sex & & & NS \\
\hline Male & $60(78.9)$ & 78.3 & \\
\hline Female & $16(21.1)$ & 87.5 & \\
\hline \multicolumn{4}{|l|}{ Status of Hepatitis } \\
\hline HBsAg positive & 62 (81.6) & 85.5 & NS \\
\hline HCVAb positive & $3(3.9)$ & 33.3 & \\
\hline Others & $11(14.5)$ & 63.6 & \\
\hline AFP level (ng/ml) & & & $<0.01$ \\
\hline Normal & $43(56.6)$ & 69.8 & \\
\hline Elevated & $33(43.4)$ & 93.9 & \\
\hline Tumor size (cm) & & & NS \\
\hline$\leq 5$ & $41(53.9)$ & 78.0 & \\
\hline$>5$ & $35(46.1)$ & 82.9 & \\
\hline TNM stage & & & NS \\
\hline I & $42(55.3)$ & 83.3 & \\
\hline$\|$ & $34(44.7)$ & 76.5 & \\
\hline Platelets (G/L) & & & NS \\
\hline$<100$ & $11(14.5)$ & 81.8 & \\
\hline$\geq 100$ & $65(85.5)$ & 80.0 & \\
\hline AST level (U/L) & & & NS \\
\hline$\leq 40$ & $54(71.1)$ & 85.2 & \\
\hline$>40$ & $22(28.9)$ & 68.2 & \\
\hline ALT level (U/L) & & & NS \\
\hline$\leq 40$ & $49(71.1)$ & 81.6 & \\
\hline$>40$ & $27(28.9)$ & 77.8 & \\
\hline GGT level (U/L) & & & NS \\
\hline$\leq 55$ & $43(56.6)$ & 81.4 & \\
\hline$>55$ & $33(43.4)$ & 78.8 & \\
\hline Albumin level(g/L) & & & NS \\
\hline$\leq 35$ & $8(10.5)$ & 75.0 & \\
\hline$>35$ & $68(89.5)$ & 80.9 & \\
\hline BIL $(\mu \mathrm{mol} / \mathrm{L})$ & & & NS \\
\hline$\leq 17.1$ & $59(77.6)$ & 78.0 & \\
\hline$>17.1$ & $17(22.4)$ & 88.2 & \\
\hline $\mathrm{PT}(\mathrm{s})$ & & & NS \\
\hline$\leq 13.3$ & $55(72.4)$ & 83.6 & \\
\hline$>13.3$ & $21(27.6)$ & 71.4 & \\
\hline Tumor grade & & & $<0.01$ \\
\hline 1 & $6(7.9)$ & 16.7 & \\
\hline 2 & $43(56.6)$ & 79.1 & \\
\hline 3 & $27(35.5)$ & 96.3 & \\
\hline All patients & 76 (100) & 80.3 & - \\
\hline
\end{tabular}

Abbreviations: $\mathrm{HBsAg}=$ hepatitis $B$ surface antigen; $\mathrm{HCV} A b=$ hepatitis $\mathrm{C}$ virus antibody; AFP = serum $\alpha$-fetoprotein; AST = serum aspartate aminotransferase level; ALT = serum alanine aminotransferase level; GGT $=$ serum $\gamma$ glutamyltransferase; $\mathrm{BIL}=$ serum total bilirubin level; $\mathrm{PT}=$ prothrombin time; NS = not significant. presence of ME included pretreatment AFP level and tumor grade. Patients with elevated pretreatment AFP level (>25 ng/ml) exhibited higher risk of ME compared with those with normal pretreatment levels $(93.9 \%$ vs. $69.8 \%, P<0.01)$. ME was more frequently detected in high-grade tumors than in low-grade tumors. ME positivity was $16.7 \%(1 / 6)$ for Grade $1,79.1 \%(34 / 43)$ for Grade 2, and 96.3\% (26/27) for Grade 3 tumors $(P<$ $0.01)$. The pretreatment hepatitis $B$ surface antigen and hepatitis $C$ virus antibody statuses; the serum levels of aspartate aminotransferase, alanine aminotransferase, $\gamma$ glutamyltransferase, total bilirubin, and albumin; platelet count; tumor size; tumor-node-metastasis (TNM) stage; and prothrombin time did not correlate with the presence of ME. On multivariate analysis, only tumor grade remained significantly and independently associated with ME positivity $(P<0.01)$.

\section{Factors associated with ME distance}

The ME distance for HCC are listed in Table 2. Of the 76 patients, the median ME distance was $1.0 \mathrm{~mm}$ (mean, $1.2 \mathrm{~mm}$; range, $0-8 \mathrm{~mm}$ ). The majority $(72 / 76$, 94.7\%) of patients had $\mathrm{ME} \leq 3.5 \mathrm{~mm}$, whereas 4 patients had ME of $4.5 \mathrm{~mm}(\mathrm{n}=2), 7.0 \mathrm{~mm}$ and $8.0 \mathrm{~mm}$, respectively. Only the tumor grade was found to significantly correlate with the distance of ME $(P<0.01)$.

Of the 76 patients, $6(7.9 \%)$ patients had tumors of Grade 1; 43 (56.6\%), of Grade 2; and 27 (35.5\%), of Grade 3. Figure 1 shows the relationship between tumor grade and the mean distance of ME, with higher grade tumors having a greater distance of ME. When evaluated by tumor grade, the distance (mean \pm SD) of ME was $0.0 \pm 0.1 \mathrm{~mm}$ (median, $0.0 \mathrm{~mm}$; range $0-0.2 \mathrm{~mm}$ ) for Grade 1, $0.9 \pm 0.9 \mathrm{~mm}$ (median, $0.80 \mathrm{~mm}$; range 0-4.5 mm) for Grade 2, and $1.9 \pm 1.9 \mathrm{~mm}$ (median, $1.5 \mathrm{~mm}$; range $0-8.0 \mathrm{~mm})$ for Grade 3 tumors $(P<0.01)$.

Figure 2 presents the cumulative distribution of the ME in patients with tumors of Grades 2 and 3. A comparison between the distributions of these 2 grades indicated that most of the Grade $2(67.4 \%)$ and Grade 3 (66.7\%) tumors had ME of 0.1-1.9 mm. Grade 1 tumors were not included in this analysis owing to the small number of patients with this tumor type, and 5 out of 6 patients did not have ME.

\section{Discussion}

Microscopic extension of the primary tumor plays a significant role in defining the CTV for radiotherapy. A quantitative pathologic assessment of subclinical tumor invasion from primary tumor or metastatic lymph nodes into adjacent tissues for planning externalbeam radiotherapy has been performed successfully for 
Table 2 ME distance $(\mathrm{mm})$ by clinical characteristics

\begin{tabular}{|c|c|c|}
\hline Characteristic & ME extent (mean $\pm S D)$ & $P$ value \\
\hline Age $(y)$ & & NS \\
\hline$\leq 60$ & $1.3 \pm 1.4$ & \\
\hline$>60$ & $1.0 \pm 1.5$ & \\
\hline Sex & & NS \\
\hline Male & $1.2 \pm 1.5$ & \\
\hline Female & $1.1 \pm 0.9$ & \\
\hline \multicolumn{3}{|l|}{ Status of Hepatitis } \\
\hline HBsAg positive & $1.3 \pm 1.5$ & NS \\
\hline HCVAb positive & $0.3 \pm 0.6$ & \\
\hline Others & $1.0 \pm 1.1$ & \\
\hline AFP level (ng/ml) & & NS \\
\hline Normal & $1.1 \pm 1.5$ & \\
\hline Elevated & $1.3 \pm 1.3$ & \\
\hline Tumor size (cm) & & NS \\
\hline$\leq 5$ & $1.2 \pm 1.3$ & \\
\hline$>5$ & $1.2 \pm 1.5$ & \\
\hline TNM stage & & NS \\
\hline 1 & $1.2 \pm 1.4$ & \\
\hline$\|$ & $1.2 \pm 1.5$ & \\
\hline Platelets (G/L) & & NS \\
\hline$<100$ & $1.3 \pm 2.0$ & \\
\hline$\geq 100$ & $1.2 \pm 1.3$ & \\
\hline AST level (U/L) & & NS \\
\hline$\leq 40$ & $1.3 \pm 1.5$ & \\
\hline$>40$ & $1.0 \pm 1.3$ & \\
\hline ALT level (U/L) & & NS \\
\hline$\leq 40$ & $1.2 \pm 1.4$ & \\
\hline$>40$ & $1.1 \pm 1.5$ & \\
\hline GGT level (U/L) & & NS \\
\hline$\leq 55$ & $1.0 \pm 0.9$ & \\
\hline$>55$ & $1.4 \pm 1.9$ & \\
\hline Albumin level(g/L) & & NS \\
\hline$\leq 35$ & $1.0 \pm 0.8$ & \\
\hline$>35$ & $1.2 \pm 1.5$ & \\
\hline BIL ( $\mu \mathrm{mol} / \mathrm{L})$ & & NS \\
\hline$\leq 17.1$ & $1.2 \pm 1.5$ & \\
\hline$>17.1$ & $1.1 \pm 1.1$ & \\
\hline PT (s) & & NS \\
\hline$\leq 13.3$ & $1.3 \pm 1.5$ & \\
\hline$>13.3$ & $1.0 \pm 1.1$ & \\
\hline Tumor grade & & $<0.01$ \\
\hline 1 & $0.0 \pm 0.1$ & \\
\hline 2 & $0.9 \pm 0.9$ & \\
\hline 3 & $1.9 \pm 1.9$ & \\
\hline All patients & $1.2 \pm 1.4$ & - \\
\hline
\end{tabular}

Abbreviations: As in table 1.

some cancers, including head-and-neck, lung, skin, prostate, and bladder cancers [14-22]. There are few relevant data available for hepatocellular carcinoma [23]. To our knowledge, this is the first prospective study to evaluate

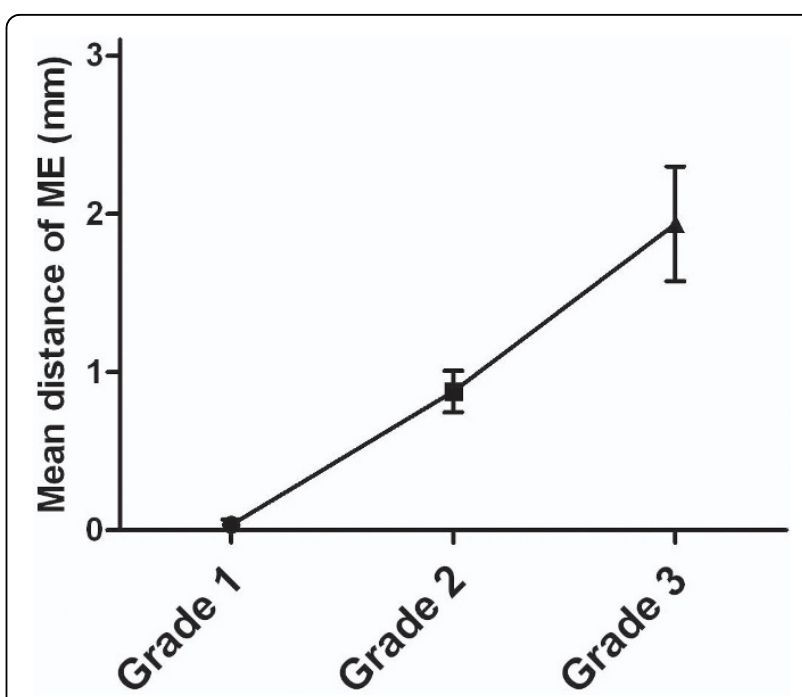

Figure 1 Correlation between tumor grades and the mean distance of microscopic extension (ME).

the ME of tumors using whole-mount preparations in patients with hepatocellular carcinoma. The present study showed that ME occurred more frequently among patients with an elevated AFP level than those with normal AFP levels. The tumor grade is significantly associated with both the presence and the extent of ME.

Developments in radiation techniques have enabled the safe delivery of dose-escalated conformal radiation to a wide spectrum of patients with inoperable HCC. Several studies have shown an improved response and survival rates with the administration of a high radiation dose in these patients [12,24-26]. The University of Michigan conducted a phase I/II trial of 128 patients with unresectable intrahepatic malignancies receiving

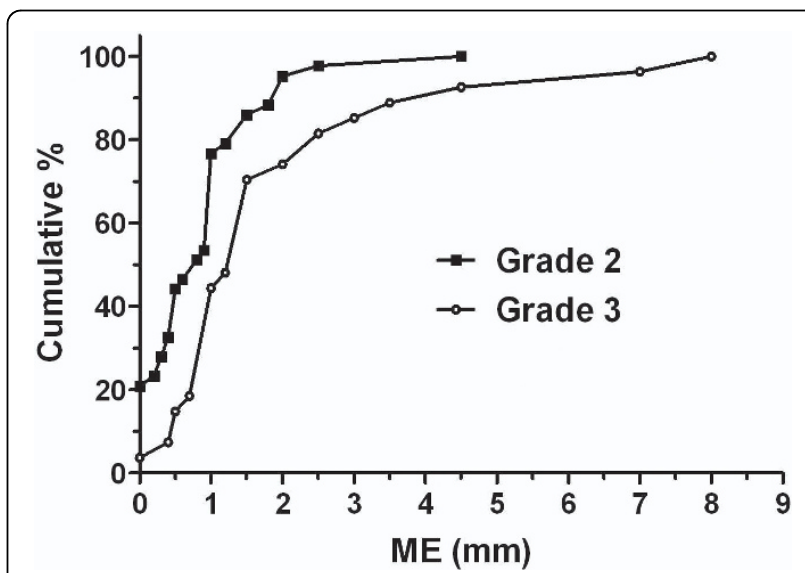

Figure 2 Cumulative distribution of microscopic extension (ME) according to tumor grade. Grade 1 was not included in this analysis due to the small number of patients with tumors of this grade, and 5 out of 6 patients did not have ME. 
3D-CRT and concurrent hepatic arterial infusion of floxuridine. Patients who received a dose $\geq 75$ Gy had significantly higher survival rates compared to those receiving a dose of $<75$ Gy (23.9 months vs. 14.9 months, $P<0.01)[24,27]$. Similarly, Park et al. and Seong et al. reported the results of a study on $158 \mathrm{HCC}$ patients classified with Child-Pugh class A or B liver disease, who were prescribed radiation doses of 25-60 Gy in daily fractions of $1.8-\mathrm{Gy}[25,28]$. The total radiation dose was found to be the only significant factor in predicting tumor response and survival. Other studies have also reported that the radiation dose appeared to be a significant prognostic factor in radiation response of patients with HCC $[11,12,26]$. However, the treatment benefits observed with increased radiation doses come at a cost because toxicity risks increase proportionally with the increases in radiation dose and large treatment volume [25]. Even in 3D-CRT or IMRT, the dose delivery for the disease is limited by the sensitivity of liver tissue to ionizing radiation. Therefore, in the case of high-dose 3D-CRT or IMRT for HCC treatment, the adequate treatment of the tumor, including the primary tumor and subclinical lesions and the radiation tolerance of the healthy surrounding tissue need to be balanced well. In other words, it is very important to estimate the microscopic extension as accurately as possible. Unfortunately, there was no precise definition of the optimal CTV margins; therefore, no optimal treatment plan for patients with HCC has been defined. Several previous studies have used a margin of $1.0 \mathrm{~cm}$ to $1.5 \mathrm{~cm}$ from the GTV to determine the CTV; this estimation of the margin is largely empirical and mainly left to the discretion of the physician. In this study, the majority (94.7\%) of patients with $\mathrm{HCC}$ had ME $\leq 3.5$ $\mathrm{mm}$, and the extent of ME depended on the tumor grade. Only 4 of 76 patients had $\mathrm{ME}>4.0 \mathrm{~mm}$ beyond the GTV. The CTV margins of $0.2,4.5$, and $8.0 \mathrm{~mm}$ beyond the gross tumor would have been adequate to cover all the ME observed in this study for tumor Grades 1, 2, and 3, respectively, in all patients with HCC. Similarly, Wang et al retrospectively reviewed 300 slides from tumor samples of 149 patients with HCC using routine histopathologic preparations and recommended GTV-to-CTV expansions of $4 \mathrm{~mm}$ with $100 \%$ accuracy [23].

The level of serum AFP is associated with both survival and intrahepatic recurrence for HCC [29-32]. Montorsi et al. reported that the level of AFP is an independent predictor of disease recurrence in patients with HCC [31]. Imamura et al. revealed that a serum AFP level $\geq 32 \mathrm{ng} / \mathrm{ml}$ contributed to early intrahepatic recurrence of HCC after hepatectomy [32]. These findings were supported by the outcome of our study, in which a high prevalence of ME was noted in patients with an elevated AFP level. A previous study confirmed that the extent of microinvasion of $\mathrm{HCC}$ was correlated with high AFP levels [23]. However, elevated AFP levels were not associated with the distance of the ME in our study, this finding requires validation with larger patient numbers. Other studies suggest that serum AFP level probably reflects the degree of cellular differentiation, and thus, the extent of the tumor invasion [33-36]. Interestingly, the presence and extent of ME of prostatic carcinomas have also shown to correlate with increased PSA levels in patients with early stages of prostate cancer $[17,18]$.

High tumor grades are associated with poor outcome for HCC patients. Shah et al. demonstrated that moderate (hazard ratio $[\mathrm{HR}], 3.0$; 95\% confidence interval [CI], 1.4-6.7) and poor (HR, 3.3; 95\% CI, 1.3-8.3) tumor differentiation is an independent predictor of recurrence after resection of HCC [37]. Cucchetti et al. analyzed the prognostic factors of recurrence after resection of HCC; the results showed that poorly differentiated and undifferentiated tumors have a higher recurrence rate (54\%) than well-differentiated and moderately differentiated tumors $(25 \% ; P=0.015)$ [38]. Wayne et al. also demonstrated that tumor grade is a risk factor for HCC recurrence after resection [39]. Our data indicated that tumor grade was significantly associated with both the presence and extent of ME. Similarly, other studies revealed a significant correlation between the extent of extracapsular extension and higher Gleason scores in prostate cancer patients $[17,18,40]$. These data may partially explain why tumor recurrence was more frequent in patients with high-grade tumors than in those with low-grade tumors.

In this series, no correlation was observed between tumor size and extent of ME in HCC, which is consistent with the findings of other studies focusing on the extent of ME in metastatic lymph nodes and primary lung cancers $[15,21]$. These correlations of the extent of ME with the pathological features of the tumor and not the tumor size signify that ME may be related to the biological characteristics of the primary tumor. In contrast, a correlation between tumor size and the presence or extent of microinvasion was observed in a previous study of 149 patients with HCC [23]. Therefore, the correlations of the extent of ME with the tumor grade or the tumor size are needed to be further validated in the near future.

This is only a prospective study to evaluate microscopic extension using whole-mount preparations of HCC; however, our study has some potential limitations. First, the slides of specimens were only representative 2-dimensional sections of the resected tumor and may not really illustrate the ME in 3 dimensions. Some ME measurements may have been slightly underestimated. 
Second, sampling error was a possibility as there were a median of 5 slides examined per patient. Third, this study addressed histologic data, not radiographic. So even though ME was found beyond the histologically visible gross disease, this does not necessarily relate to the CTV and GTV, as used in radiation therapy, which are radiographically based definitions. Fourth, tissue shrinkage was not taken into consideration in this study. In a well-designed analysis of patients with prostate cancer, Schned et al. observed only $4.3 \%$ linear tissue shrinkage between the microscopic slide and the fresh specimen [41]. From a volumetric standpoint, it can be postulated that tissue shrinkage is lesser in HCC than in prostate cancer, owing to the presence of smooth muscles in the prostate gland and the absence of myofibroblastic cells in the liver parenchyma and neoplasms. Thus, it can be assumed that tissue shrinkage may be much smaller, perhaps even negligible.

\section{Conclusions}

In summary, our clinicopathologic analysis indicated that the incidence of ME positively correlated with elevated AFP levels and high grades of tumor and that the extent of ME appears to be related only to the tumor grade. Although the optimal CTV of HCC remains undefined, it is reasonable to recommend CTV margins extending to $\leq 8 \mathrm{~mm}$ beyond the GTV for all tumor grades in patients with HCC.

\footnotetext{
Author details

'Department of Radiation Oncology, Cancer Hospital, Chinese Academy of Medical Sciences (CAMS) and Peking Union Medical College (PUMC), Beijing 100021, P.R. China. ${ }^{2}$ Department of Pathology, Cancer Hospital, Chinese Academy of Medical Sciences (CAMS) and Peking Union Medical College (PUMC), Beijing 100021, P.R. China.
}

\section{Authors' contributions}

WW andYL designed the study, with assistance from XF. XF and WW analyzed the data. All authors helped to interpret the findings. WW wrote the manuscript, which was approved by all authors.

\section{Competing interests}

The authors declare that they have no competing interests.

Received: 24 June 2010 Accepted: 23 August 2010

Published: 23 August 2010

\section{References}

1. Parkin DM, Bray F, Ferlay J, et al: Estimating the world cancer burden: GLOBOCAN 2000. Int J Cancer 2001, 94:153-156.

2. Jemal A, Siegel R, Ward E, et al: Cancer statistics, 2009. CA Cancer J Clin 2009, 59:225-249.

3. Zhang SW, Chen WQ, Lei ZL, et al: A report of cancer incidence from 37 cancer registries in China, 2004. China Cancer 2008, 17:909-912.

4. Chen WQ, Zhang SW, Kong LZ, et al: Cancer mortality report of 34 cancer registries in China, 2004. China Cancer 2008, 17:913-916.

5. Llovet JM, Burroughs A, Bruix J: Hepatocellular carcinoma. Lancet 2003, 362:1907-1917.

6. Llovet JM: Updated treatment approach to hepatocellular carcinoma. J Gastroenterol 2005, 40:225-235.
7. Choi TK, Edward CS, Fan ST, et al: Results of surgical resection for hepatocellular carcinoma. Hepatogastroenterology 1990, 37:172-175.

8. Nagorney DM, van Heerden JA, Ilstrup DM, et al: Primary hepatic malignancy: surgical management and determinants of survival. Surgery 1989, 106:740-748

9. Hawkins MA, Dawson LA: Radiation therapy for hepatocellular carcinoma: from palliation to cure. Cancer 2006, 106:1653-1663.

10. Fukumitsu N, Sugahara S, Nakayama H, et al: A prospective study of hypofractionated proton beam therapy for patients with hepatocellular carcinoma. Int J Radiat Oncol Biol Phys 2009, 74:831-836.

11. Park W, Lim DH, Paik SW, et al: Local radiotherapy for patients with unresectable hepatocellular carcinoma. Int I Radiat Oncol Biol Phys 2005, 61:1143-1150.

12. Mornex F, Girard N, Beziat C, et al: Feasibility and efficacy of high-dose three-dimensional radiotherapy in cirrhotic patients with small-size hepatocellular carcinoma non-eligible for curative therapies-mature results of the French phase II RTF-1 trial. Int I Radiat Oncol Biol Phys 2006, 66:1152-1158

13. Kim TH, Kim DY, Park JW, et al: Three-dimensional conformal radiotherapy of unresectable hepatocellular carcinoma patients for whom transcatheter arterial chemoembolization was ineffective or unsuitable. Am J Clin Oncol 2006, 29:568-575.

14. Jenkins P, Anjarwalla S, Gilbert $\mathrm{H}$, et al: Defining the clinical target volume for bladder cancer radiotherapy treatment planning. Int I Radiat Oncol Biol Phys 2009, 75(5):1379-84.

15. Apisarnthanarax S, Elliott DD, El-Naggar AK, et al: Determining optimal clinical target volume margins in head-and neck cancer based on microscopic extracapsular extension of metastatic neck nodes. Int $J$ Radiat Oncol Biol Phys 2006, 64:678-683.

16. Yuan S, Meng X, Yu J, et al: Determining optimal clinical target volume margins on the basis of microscopic extracapsular extension of metastatic nodes in patients with non-small cell lung cancer. Int I Radiat Oncol Biol Phys 2007, 67:727-734.

17. Chao KK, Goldstein NS, Yan D, et al: Clinicopathologic analysis of extracapsular extension in prostate cancer: should the clinical target volume be expanded posterolaterally to account for microscopic extension? Int I Radiat Oncol Biol Phys 2006, 65:999-1007.

18. Schwartz DJ, Sengupta S, Hillman DW, et al: Prediction of radial distance of extraprostatic extension from pretherapy factors. Int I Radiat Oncol Biol Phys 2007, 69:411-418.

19. Teh BS, Bastasch MD, Wheeler TM, et al: IMRT for prostate cancer: defining target volume based on correlated pathologic volume of disease. Int $J$ Radiat Oncol Biol Phys 2003, 56:184-191.

20. Grills IS, Fitch DL, Goldstein NS, et al: Clinicopathologic analysis of microscopic extension in lung adenocarcinoma: defining clinical target volume for radiotherapy. Int J Radiat Oncol Biol Phys 2007, 69:334-341.

21. Giraud P, Antoine M, Larrouy A, et al: Evaluation of microscopic tumor extension in non-small-cell lung cancer for three-dimensional conformal radiotherapy planning. Int J Radiat Oncol Biol Phys 2000, 48:1015-1024.

22. Choo R, Woo T, Assaad D, et al: What is the microscopic tumor extent beyond clinically delineated gross tumor boundary in nonmelanoma skin cancers? Int J Radiat Oncol Biol Phys 2005, 62:1096-1099.

23. Wang MH, Ji Y, Zeng ZC, et al: Impact Factors for Microinvasion in Patients with Hepatocellular Carcinoma: Possible Application to the Definition of Clinical Tumor Volume. Int J Radiat Oncol Biol Phys 2009.

24. Dawson LA, McGinn CJ, Normolle D, et al: Escalated focal liver radiation and concurrent hepatic artery fluorodeoxyuridine for unresectable intrahepatic malignancies. J Clin Oncol 2000, 18:2210-2218.

25. Park HC, Seong J, Han KH, et al: Dose-response relationship in local radiotherapy for hepatocellular carcinoma. Int I Radiat Oncol Biol Phys 2002, 54:150-155.

26. Liu MT, Li SH, Chu TC, et al: Three-dimensional conformal radiation therapy for unresectable hepatocellular carcinoma patients who had failed with or were unsuited for transcatheter arterial chemoembolization. Jpn J Clin Oncol 2004, 34:532-539.

27. Ben-Josef E, Normolle D, Ensminger WD, et al: Phase II trial of high-dose conformal radiation therapy with concurrent hepatic artery floxuridine for unresectable intrahepatic malignancies. J Clin Oncol 2005, 23:8739-8747. 
28. Seong J, Park HC, Han KH, et al: Clinical results and prognostic factors in radiotherapy for unresectable hepatocellular carcinoma: a retrospective study of 158 patients. Int J Radiat Oncol Biol Phys 2003, 55:329-336.

29. Carr BI, Buch SC, Kondragunta V, et al: Tumor and liver determinants of prognosis in unresectable hepatocellular carcinoma: A case cohort study. J Gastroenterol Hepatol 2008, 23:1259-1266.

30. Changchien CS, Chen CL, Yen YH, et al: Analysis of 6381 hepatocellular carcinoma patients in southern Taiwan: Prognostic features, treatment outcome, and survival. J Gastroenterol 2008, 43:159-170.

31. Montorsi M, Santambrogio R, Bianchi P, et al: Survival and recurrences after hepatic resection or radiofrequency for hepatocellular carcinoma in cirrhotic patients: a multivariate analysis. J Gastrointest Surg 2005, 9:62-67.

32. Imamura $H$, Matsuyama $Y$, Tanaka $E$, et al: Risk factors contributing to early and late phase intrahepatic recurrence of hepatocellular carcinoma after hepatectomy. J Hepatol 2003, 38:200-207.

33. Chevret S, Trinchet JC, Mathieu D, et al: A new prognostic classification for predicting survival in patients with hepatocellular carcinoma. J Hepatol 1999, 31:133-141.

34. Hanazachi K, Kajikawa S, Koide N, et al: Prognostic factors after hepatic resection for hepatocellular carcinoma with hepatitis $C$ viral infection: Univariate and multivariate analysis. Am J Gastroenterol 2001, 96:1243-1250.

35. Matsumoto K, Yoshimoto J, Sugo H, et al: Relationship between the histological degrees of hepatitis and the postoperative recurrence of hepatocellular carcinoma in patients with hepatitis C. Hepatol Res 2002, 23:196-201.

36. Harrison $L E H$, Koneru $B$, Baramipour $P$, et al: Locoregional recurrences are frequent after radiofrequency ablation for hepatocellular carcinoma. J Am Coll Surg 2003, 197:759-764

37. Shah S, Cleary SP, Wei MA, et al: Recurrence after liver resection for hepatocellular carcinoma: Risk factors, treatment, and outcomes. Surgery 2007, 141:330-339

38. Cucchetti A, Vivarelli M, Piscaglia F, et al: Tumor doubling time predicts recurrence after surgery and describes the histological pattern of hepatocellular carcinoma on cirrhosis. J Hepatol 2005, 43:310-316.

39. Wayne JD, Lauwers GY, Ikai I, et al: Preoperative predictors of survival after resection of small hepatocellular carcinomas. Ann Surg 2002, 235:722-731.

40. Wheeler TM, Dillioglugil O, Kattan MW, et al: Clinical and pathological significance of the level and extent of capsular invasion in clinical stage T1-2 prostate cancer. Hum Pathol 1998, 29:856-862.

41. Schned A, Wheeler $K$, Hodorowski $C$, et al: Tissue-shrinkage correction factor in the calculation of prostate cancer volume. Am J Surg Pathol 1996, 20:1501-1506.

doi:10.1186/1748-717X-5-73

Cite this article as: Wang et al:: Prospective evaluation of microscopic extension using whole-mount preparation in patients with hepatocellular carcinoma: Definition of clinical target volume for radiotherapy. Radiation Oncology 2010 5:73.

\section{Submit your next manuscript to BioMed Central and take full advantage of:}

- Convenient online submission

- Thorough peer review

- No space constraints or color figure charges

- Immediate publication on acceptance

- Inclusion in PubMed, CAS, Scopus and Google Scholar

- Research which is freely available for redistribution

Submit your manuscript at www.biomedcentral.com/submit
CioMed Central 